\title{
Weed control in Mexican Irrigation Districts with lightweight equipment
}

\author{
R. Lomeli \\ Mexican Institute of Water Technology, Mexico
}

\begin{abstract}
In Mexico, mechanical weed control was traditionally carried out with inadequate equipment, which caused damage to the slopes and changes in the hydraulic section. In order to solve this problem, lightweight equipment is currently being used to allow the development of a vegetation cover to retain soil with no interference with water flow, reducing erosion and maintaining stable conditions in the slopes. This paper addresses aspects related to the characteristics and criteria for selecting and sequencing tools for use. The costs of weed control in irrigation channels, drains and roads have been reduced by $39.21 \%$ compared to using inadequate equipment. The versatility of lightweight equipment allows the use of the most appropriate implement for each weed. In Mexico, the current inventory includes 290 lightweight devices with which a potential weed control of $90 \%$ can be obtained in channels and $70 \%$ in drains of the Irrigation Districts.

Keywords: maintenance equipment, Irrigation Districts, weed control, lightweight.
\end{abstract}

\section{Introduction}

In Mexico, only 6 million hectares of the 21 million hectares cropped annually are irrigated - the remaining 15 million hectares are dry-cropped. However, over half of the countries income derived from agriculture comes from the irrigated land. The irrigated land is grouped into 85 Irrigation Districts - covering 3.5 million hectares, and 27,000 small Irrigation Units - covering 2.5 million hectares. Productivity in the irrigated lands is directly related to the operating conditions of the irrigation systems $[1,2]$.

The infrastructure inventory of the Irrigation Districts in Mexico indicates 31,118 miles of canals, 7,857 miles of which are main canals and 23,261 are 
secondary canals, $48 \%$ of all them are lining. The drainage network is 19,368 miles, 5,944 miles of which are collector drains and 13,424 are secondary drains. The road network is 46,602 miles [3].

Table 1 is a summary table of the classification of canals and drains, according to their main characteristics which are the bottom and the depth of water, as shown in Figure 1.

Table 1: Characteristics and percentages within the national territory of canals and drains.

\begin{tabular}{|c|c|c|c|c|}
\hline \multirow{2}{*}{ Type } & \multirow{2}{*}{ Bottom } & \multirow{2}{*}{ Depth of water } & Canals & Drains \\
\hline & & & $(\%)$ & $(\%)$ \\
\hline $\mathrm{E}$ & Less than $6^{\prime} 7^{\prime \prime}$ & Less than $3^{\prime} 11.4^{\prime \prime}$ & 76.2 & 40.4 \\
\hline $\mathrm{D}$ & $\begin{array}{l}\text { Between } 6^{\prime} 7^{\prime \prime} \text { and } \\
13^{\prime} 1.4^{\prime \prime}\end{array}$ & $\begin{array}{l}\text { Between 3' 11.4'" and } \\
5^{\prime} 7^{\prime \prime}\end{array}$ & 13.8 & 28.9 \\
\hline $\mathrm{C}$ & $\begin{array}{l}\text { Between 13' 1.4" and } \\
19^{\prime} 8.2^{\prime \prime}\end{array}$ & $\begin{array}{l}\text { Between 5' 7' and } \\
7^{\prime} 10.4 "\end{array}$ & 5.4 & 16.9 \\
\hline B & $\begin{array}{l}\text { Between } 19^{\prime} 8.2^{\prime \prime} \text { and } \\
32^{\prime} 9.7 \text { " }\end{array}$ & $\begin{array}{l}\text { Between } 7^{\prime} 10.4^{\prime \prime} \text { and } \\
9^{\prime} 10^{\prime \prime}\end{array}$ & 1.4 & 8 \\
\hline $\mathrm{A}$ & $\begin{array}{l}\text { Between } 32^{\prime} 9.7^{\prime \prime} \text { and } \\
65^{\prime} 7.4^{\prime \prime}\end{array}$ & More than $9^{\prime} 10^{\prime \prime}$ & 3.2 & 5.8 \\
\hline
\end{tabular}

\section{Canals and drains cross section}

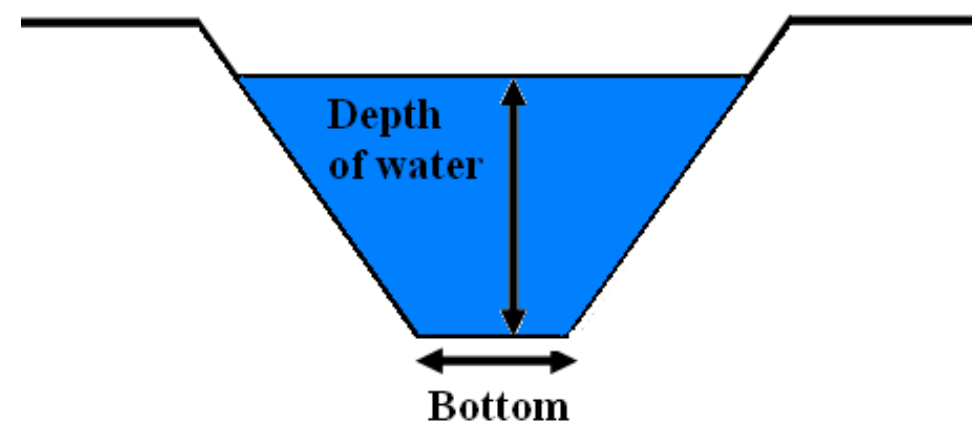

Figure 1: Cross section of canals and drains.

Overall one third of the budget for the maintenance of Irrigation Districts is used to control weeds in canals, drains and roads, mainly by mechanical method.

In the early nineties, to perform the weed control in Irrigation Districts, heavy machinery was used (which is designed for building works than to the infrastructure maintenance), which was expensive and propitiate the deterioration of hydraulic section of the infrastructure. 
Figure 2 presents a representative sample of the machinery inventory Irrigation Districts in 1992 which consisted mainly of draglines and bulldozers, excavators began to be used and there were some backhoe loaders for use in medium and small channels and drains and a comparative inventory of the same Irrigation Districts in 2011.

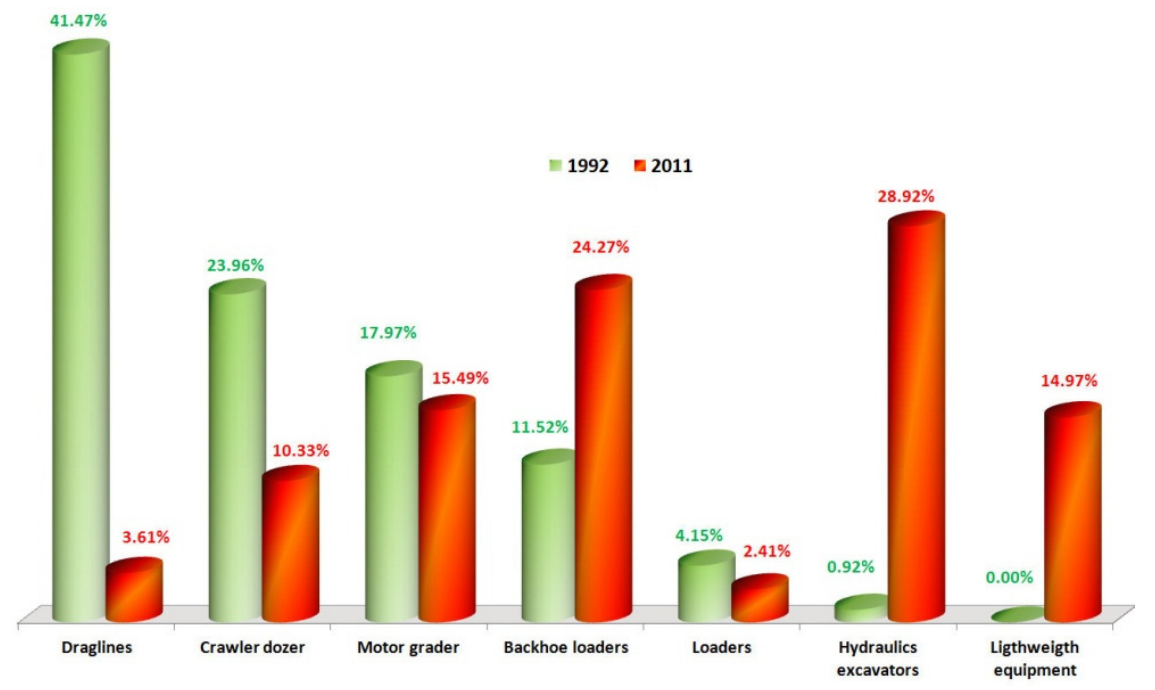

Figure 2: Comparative analysis of machinery and equipment inventories.

\section{Problems}

The investment in infrastructure for irrigation is high, one new hectare of land (dam construction, infrastructure, etc.) costs over $€ 5000$, the infrastructure rehabilitation requires approximately $€ 1000$, while maintenance has a cost of about $€ 18$, making it extremely profitable to perform the work of preserving the infrastructure of the irrigation districts to obtain sustainable water use.

Approximately $60 \%$ of the Irrigation District budget is allocated to the maintenance of the work and to overcoming problems related to silt accumulation and the proliferation of aquatic and terrestrial weeds and of this number almost a third of the budget is used for the extraction of weeds in canals and drains [4].

\section{Characteristics of lightweight equipment}

In Mexico, the lightweight equipment used for weed control is a farm tractor with an electro-hydraulic control system and a hydraulic arm (with a reach of $31^{\prime} 2$ " in length and 14' 5" in depth). Various implements are available for the hydraulic arm. This combination of equipment allows mobility for works on roadsides and on the slopes, bottom and edge of canals and drains. The electro-hydraulic system allows maneuverability of the arm and quick and easy operation. 
There are three kinds of implements currently available in Mexico. These are: the sickle bar, the mowers and the mowing buckets.

Sickle bar - Designed to cut soft-stemmed plants with stalks of all lengths. The cut vegetation is removed when is a possibility that downstream causes blockages.

Mowers - There are two kinds of mowers available with different cutting mechanisms. One has two metallic cutting blades set on a vertical axis, that spin at high speed parallel to the ground, cutting an area 5' 3" wide.

The second kind is made up of a rotor with short perpendicular clappers that spin rapidly to chop the weeds, cutting. Mowers are recommended for the control of weeds that have stiff, woody stalks.

Mowing bucket - This is a basket used to catch the weeds as the blade cuts them. It is useful for soft-stemmed weeds on the walls and edges of canals and for the aquatic weeds in the canals and drains. The width of the cut length is $10^{\prime}$.

In order to determine which of the accessories most applicable, consideration is should be given to the stem's resistance to cut rather than its diameter.

The sickle bar and the mowing bucket are best used for soft-stemmed plants that can easily broke by hand. The mowers are best used for woody stemmed plants that may be cut with a blade.

If the plants require several chops using a sharp blade then the use of lightweight equipment should be avoided.

As weeds should be cut prior to flowering to prevent the scattering of seeds, each Irrigation District has an individual program for weed control, which is dependent on the characteristics of the weeds and the local climate.

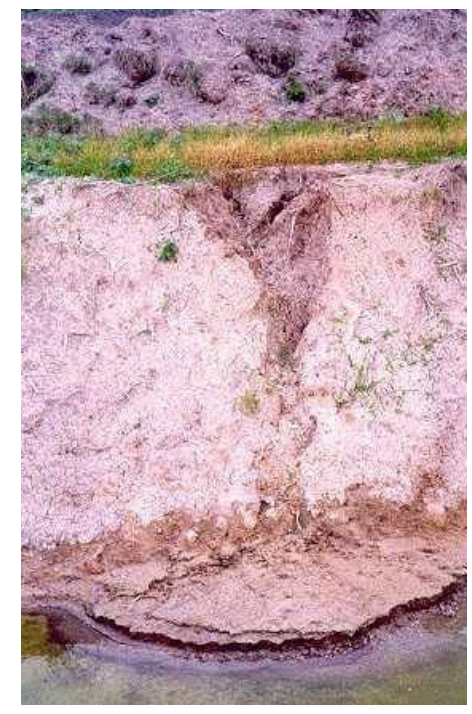

Figure 3: Unprotected slopes causes accumulation of sediments in canals. 


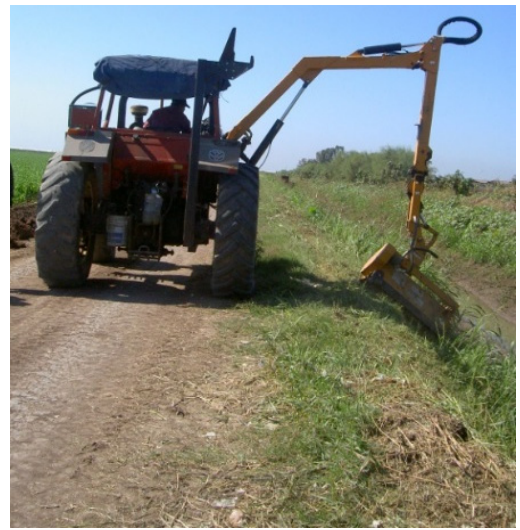

Figure 4: Lightweight equipment in an irrigation canal.

\section{Technology transfer}

Initially, all lightweight equipment was transferred to the user associations, which now operate and maintain the Irrigation Districts with the cooperation and participation of the technical personnel in the district. A three-phase strategy was development for technology transfer.

The first phase focused on the applicability and use of the technology including the conservation and maintenance aspects.

The second phase concentrated on the training needs of the users to implement the technology.

A communications program was the established in the third phase, which included production of audiovisual material.

In order to assist the users in the safe and efficient use of lightweight equipment, user manuals and application guidelines were developed. In order to evaluate equipment behavior, a grading system was introduced, for: cost per hour, difficulty to cut and extract weeds, results, direct expenses, and maintenance and conservation costs.

As irrigation works maintenance has to be considered within a general maintenance scheme which in turn depends on the General Irrigation Program of the Irrigation District, a work schedule was programmed for the lightweight equipment within the general conservation and maintenance program.

A train-the-trainer method was initially carried out, starting with the technical personnel of the Mexican National Water Commission and selected members of the user association. Training then changed to a filter-down approach. The courses were offered, on site or on neighboring sites. During the train-trainer courses, a theoretical and practical approach was used for training in; background information, descriptions of equipment, operation and maintenance, programming, costs per hour, standards and equipment evaluation procedures.

A brochure and two video programs were developed and distributed around the district to aid in the assimilation of the technology. 


\section{Results and discussion}

As a result of this process of identification, validation and transfer of technology for the use of lightweight equipment in Mexico and a program of modernization of the machinery has been possible to replace the heavy machinery that was used for weed control team light performing such work efficiently and economically, dredges have been reduced from $41.47 \%$ to $3.61 \%$, has been increased significantly the number of hydraulic excavators, considering that the capacity of the buckets of dredges vary from $3 / 4$ to $1 \frac{1}{2}$ and of excavators ranging from $1 / 2$ to $3 / 4$ cubic yard capacity but with increased efficiency.

The backhoe loader currently used primarily for sediment removal work (dredging), excavation and filling for pipe laying level and distribution networks and plot extraction and loading to fill dikes and berms and liner paths. The lightweight equipment is used for weed control and removal of aquatic and terrestrial channels and drains.

The evaluation and validation of the technology was performed on sections of selected channels and drains with similar characteristics, where teams worked backhoe light and with several repetitions. Yields obtained are presented in Table 2 .

Table 2: Field yields with lightweight equipment and backhoe loaders.

\begin{tabular}{|l|c|c|c|}
\hline \multirow{2}{*}{\multicolumn{1}{|c|}{ Machine Type }} & \multicolumn{3}{|c|}{ Yields in hectares/effective hour } \\
\cline { 2 - 4 } & Maximum & Minimum & Average \\
\hline $\begin{array}{l}\text { Lightweight } \\
\text { equipment }\end{array}$ & 0.0732 & 0.1324 & 0.0948 \\
\hline Backhoe loader & 0.0567 & 0.1027 & 0.0797 \\
\hline
\end{tabular}

Addition costs were determined by effective hour of work and operation, with the cost per hour and average yield were obtained unit prices for the same type of work with both types of machines, shown in Table 3 .

Table 3: Cost analysis of weed control works.

\begin{tabular}{|l|c|c|}
\hline \multirow{2}{*}{\multicolumn{1}{|c}{ Concept }} & \multicolumn{2}{c|}{ Euros } \\
\cline { 2 - 3 } & $\begin{array}{c}\text { Lightweight } \\
\text { equipment }\end{array}$ & Backhoe loader \\
\hline Hourly effective cost & 16.09 & 21.59 \\
\hline Operation cost & 6.97 & 8.92 \\
\hline Unit price per hectare & 13.06 & 21.48 \\
\hline
\end{tabular}

The weed control works with lightweight equipment are $39.21 \%$ lower than the backhoe loader under the same working conditions deteriorate further that no hydraulic section and operating costs of the equipment are also lower light. 


\section{Conclusions}

Work in an Irrigation District requires an integral program that contemplates both conservation and maintenance. Conservation generally requires heavy weight machinery whilst maintenance is now associated with lightweight equipment.

The lightweight equipment may be used for weed control task along $90 \%$ of the supply canals and $70 \%$ of the drainage network in the irrigation district.

The preliminary results for use of lightweight equipment under standard working conditions are satisfactory. The equipment does not damage the slopes and allows the development of covering vegetation that serves to protect the canals.

The constant use of lightweight equipment in proper working conditions, has allowed work on weed control channel drains and roads in a timely, efficient and economical. Because of their versatility, they can use the implement appropriate for each type of weed, not deteriorating infrastructure and allows the development of a vegetative layer that protects the slopes, this situation prevents soil part of the drop to the river embankments and causing the accumulation of silt.

Currently in Mexico have been acquired 290 light equipment in the Irrigation Districts, which has resulted in a $39.21 \%$ reduction in the cost of weed control works on infrastructure and there is great potential for use as that $90 \%$ of the canals and drains $70 \%$ of the Irrigation Districts, are of types D and E, which are less than $19^{\prime} 8.2$ " bottom and 7' 10.4" depth.

\section{References}

[1] Water National Commission. Irrigated areas and volumes of water distributed in the irrigation districts. 2009.

[2] Water National Commission. Statistics of irrigation districts. 2009.

[3] Water National Commission. Inventories of infrastructure, machinery and equipment of the irrigation districts. 2010.

[4] Lomelí Villanueva José Ramón y Nazario Álvarez González. Importance of the Conservation of Irrigation Infrastructure in Mexico. Proceedings of the XII and II National Meeting of Latin America and the Caribbean on feedback systems and Rainwater Harvesting, Queretaro, México. 2006. 